OPEN ACCESS

Edited by:

Tetyana Milojevic

University of Vienna, Austria

Reviewed by:

Ricardo Amils,

Autonomous University of

Madrid, Spain

Elisabeth Grohmann,

Beuth Hochschule für Technik

Berlin, Germany

*Correspondence:

Cyprien Verseux

cyprien.verseux@zarm.uni-bremen.de

Specialty section:

This article was submitted to

Astrobiology,

a section of the journal

Frontiers in Astronomy and Space

Sciences

Received: 23 February 2020

Accepted: 11 May 2020

Published: 23 June 2020

Citation:

Verseux C (2020) Bacterial Growth at

Low Pressure: A Short Review.

Front. Astron. Space Sci. 7:30.

doi: 10.3389/fspas.2020.00030

\section{Bacterial Growth at Low Pressure: A Short Review}

\author{
Cyprien Verseux*
}

Laboratory of Applied Space Microbiology, Center of Applied Space Technology and Microgravity (ZARM), University of Bremen, Bremen, Germany

Biological life-support systems could greatly increase the sustainability of crewed missions to the Moon or Mars. Understanding how bacteria react to hypobaria is critical to their optimization: if enclosed within crewed compartments, microbial modules may be exposed to the lower-than-Earth atmospheric pressure considered for future space vehicles and habitats and, if deployed outside, they would best rely on a low pressure to minimize both engineering constraints and risks of leakage. Bacterial behavior at low pressures is of relevance to other fields as well, both within astrobiology (e.g., habitability and planetary protection) and outside of it (e.g., aerobiology and food preservation). Unfortunately, while microbial survival under vacuum has been largely investigated, little work has focused on metabolism at low but growth-permissive pressures. Nonetheless, recent studies brought some insights. Limits were outlined: a few bacterial species can grow just above water's triple point, more can multiply down to around 25 mbar, and shifting pressure within 100 mbar to 1 bar seems not to largely affect growth of most species when the partial pressures of metabolizable gases are not limiting. Some mediating mechanisms have been proposed: hypobaria can affect bacteria by desiccation, via a reduced availability of specific gases, and through various other physico-chemical effects, interdependent and dependent on other environmental factors. A limited number of studies also gave insights into how bacteria cope with low pressure, and how much they can adapt to it. But, overall, much remains to be discovered on bacterial growth under hypobaric conditions.

Keywords: low pressure, hypobaria, life-support systems, hypobarophiles, hypopiezotolerance, space exploration

\section{INTRODUCTION}

Data is scarce on how microorganisms cope with low pressure. As space microbiology progresses and practical applications are looming, this area should no longer be neglected.

Among those applications is the development of biological life-support systems (BLSS), of which microorganisms may be critical components (Godia et al., 2002; Hendrickx and Mergeay, 2007; Verseux et al., 2016a). First, if enclosed within crewed compartments, for instance to contribute to air revitalization, they may be exposed to atmospheric conditions differing from Earth's: future space vehicles, and Moon and Mars habitats, may rely on a lower total pressure and increased $\mathrm{O}_{2}$ concentration (e.g., 0.55 bar, $32 \% \mathrm{O}_{2}$; NASA, 2006) for engineering considerations (notably, to reduce the mass of structural components), for reducing the amounts of necessary gas consumables, and to facilitate extravehicular activities while maintaining low risks of decompression sickness (e.g., NASA, 2006; Norcross et al., 2013). Second, if BLSS modules are deployed outside to spread over larger surfaces, to rely on local resources, or both, they would best rely on low pressures 
to increase cost-efficiency, to reduce engineering constraints, and to minimize risks of outward contamination (e.g., Boston, 1981; Richards et al., 2006). On Mars, relying on a gas composition close to ambient could allow for more efficient use of atmospheric carbon and nitrogen (Verseux et al., 2016b).

Knowledge on bacterial behavior under hypobaric conditions could also help assess Mars's habitability, both to identify where indigenous life may exist and to develop appropriate planetary protection strategies. Measured values of Mars's surface pressure have varied between $\sim 6$ and $11 \mathrm{hPa}$ (sol average), with large seasonal and diurnal variations (see Harri et al., 2014; Martínez et al., 2017). Aside from their limiting the stability of liquid water at Mars's temperatures (see Figure 1; whether liquid water could persist at the surface or in the subsurface is largely discussed elsewhere, for instance in Haberle et al., 2001; Orosei et al., 2018; Hecht, 2002; Sori and Bramson, 2019), low pressures may limit microbial metabolism in potential Martian habitats.

The rationale for studying bacteria's lower pressure limits extends outside of astrobiology. To aerobiology, for instance: viable microbes (especially bacteria) abound in the troposphere (DeLeon-Rodriguez et al., 2013), and some were isolated from the stratosphere and mesosphere (Smith et al., 2010; Smith, 2013). Airborne dissemination may be an essential part of the life cycle of many microorganisms (Morris et al., 2011) and, in turn, those may have a significant impact on atmosphere chemistry and hydrological cycles (DeLeon-Rodriguez et al., 2013). It is unclear whether airborne microorganisms are metabolically active. A better understanding of microbial abilities to cope with high atmospheric conditions, including low pressures, is desirable.

Various other applications on Earth or beyond, from food packaging (Arashisar et al., 2004; Burg, 2004) to ecopoiesis (McKay et al., 1991; Thomas et al., 2006), would benefit from research on microbial metabolism at low pressures.

Unfortunately, little work has focused on this area. Elements of answers can nonetheless be drawn from various studies; they are summarized below, with the intention to provide researchers venturing into hypobare microbiology with an overview of the field and, perhaps, some research directions. It is noteworthy that, when this short article was in its final writing phase, Schwendner and Schuerger (2020) published a review on microbial activity under low pressure, which the reader is invited to consult for some further information (notably on experimental methods). Here the focus is on bacteria, with occasional comparisons with fungi or eukaryotic microalgae. The reader interested in plants under hypobaria is referred to a review by Paul and Ferl (2006).

\section{BACTERIAL GROWTH AS A FUNCTION OF ATMOSPHERIC PRESSURE}

\section{Vacuum}

Microorganisms have numerous times been exposed to pressures below water's triple point ( $6.1 \mathrm{mbar}, 0.01^{\circ} \mathrm{C}$; Haynes, 2017), both in space and on the ground (e.g., Cottin et al., 2017; Martins et al., 2017; de Vera et al., 2019). At those pressures, water is either solid or gaseous (depending on temperature), and in most microbiology experiments such vacuum led to desiccation. While some bacteria can survive desiccation (see for instance Billi and Potts, 2002; Cortesão et al., 2019; Beblo-Vranesevic et al., 2020) and rare microbial species are capable of metabolism at a water activity below 0.6 (Stevenson et al., 2017; Steinle et al., 2018), most are inactive below $0.9 \mathrm{a}_{\mathrm{w}}$ (Stevenson et al., 2015).

\section{Mars-Like Pressure}

Above its triple point, water remains stable with respect to boiling and freezing within a range of temperatures. Growth on solid medium was reported at 7 mbar (in a hypobaric desiccator flushed with $\mathrm{CO}_{2}$ and maintained at $0^{\circ} \mathrm{C}$ ) for bacterial species from various genera: Carnobacterium (Nicholson et al., 2013; Schuerger and Nicholson, 2016), Serratia (Schuerger et al., 2013; Schuerger and Nicholson, 2016), Bacillus, Clostridium, Cryobacterium, Paenibacillus, Rhodococccus, Streptomyces, Carnobacterium, Exiguobacterium, and Trichococcus (Schuerger and Nicholson, 2016).

From the environmental samples where those organisms were found, no fungi or archaea were isolated that could grow at 7 mbar, suggesting that this ability is limited to bacteria (Schuerger and Nicholson, 2016). However, reports were made of metabolic activity (albeit no growth) in lichens under similarly low pressures. Xanthoria elegans seemed to maintain its photosynthetic activity (as assessed by PAM fluorometry) in both ambient and $95 \%-\mathrm{CO}_{2}$ atmosphere down to close to 6 mbar (de Vera et al., 2010). The authors hypothesized that, under ambient air composition, the fungal symbiont may have been the source of $\mathrm{CO}_{2}$ for photosynthesis. Another lichen, Pleopsidium chlorophanum, showed similar abilities under $95 \%$ $\mathrm{CO}_{2}$ at 800 mbar total. Photosynthetic activity even seemed to increase over time, suggesting a physiological adaptation (de Vera et al., 2014). This capacity is most likely uncommon among photosynthetic microorganisms, as illustrated by the failure of the cyanobacterium Plectonema boryanum (not part of a lichen) to produce measurable $\mathrm{O}_{2}$ under similar atmospheric conditions (Kleina et al., 2019).

\section{5 to 100 mbar}

More and more species can grow as pressure increases but, among a high number of tested bacterial strains (excluding those mentioned above), only a few could grow at 25 mbar under either high $\mathrm{CO}_{2}$ or ambient air composition (Schuerger et al., 2013). For those that could (belonging to the genera Escherichia, Bacillus, Enterococcus, Proteus, Staphylococcus, and Paenibacillus), 25 mbar was close to the lower limit (Schuerger and Nicholson, 2006; Schuerger et al., 2006, 2013; Nicholson et al., 2010). In one experiment where Escherichia coli and Serratia liquefaciens were grown at $20^{\circ} \mathrm{C}$ in a $\mathrm{CO}_{2}$ atmosphere, cell densities after 7 days were similar under 1,013, 100, and 25 mbar (Berry et al., 2010). However, no intermediate cell counts were performed, and growth rates could consequently not be compared.

Between 25 and 100 mbar, growth inhibition in most bacteria seems to decrease with increasing pressure. As an example, growth rates and cell counts after $24 \mathrm{~h}$ of Bacillus subtilis 168 decreased semilogarithmically when lowering pressure from 100 to 75 and 50 mbar (Nicholson et al., 2010). 


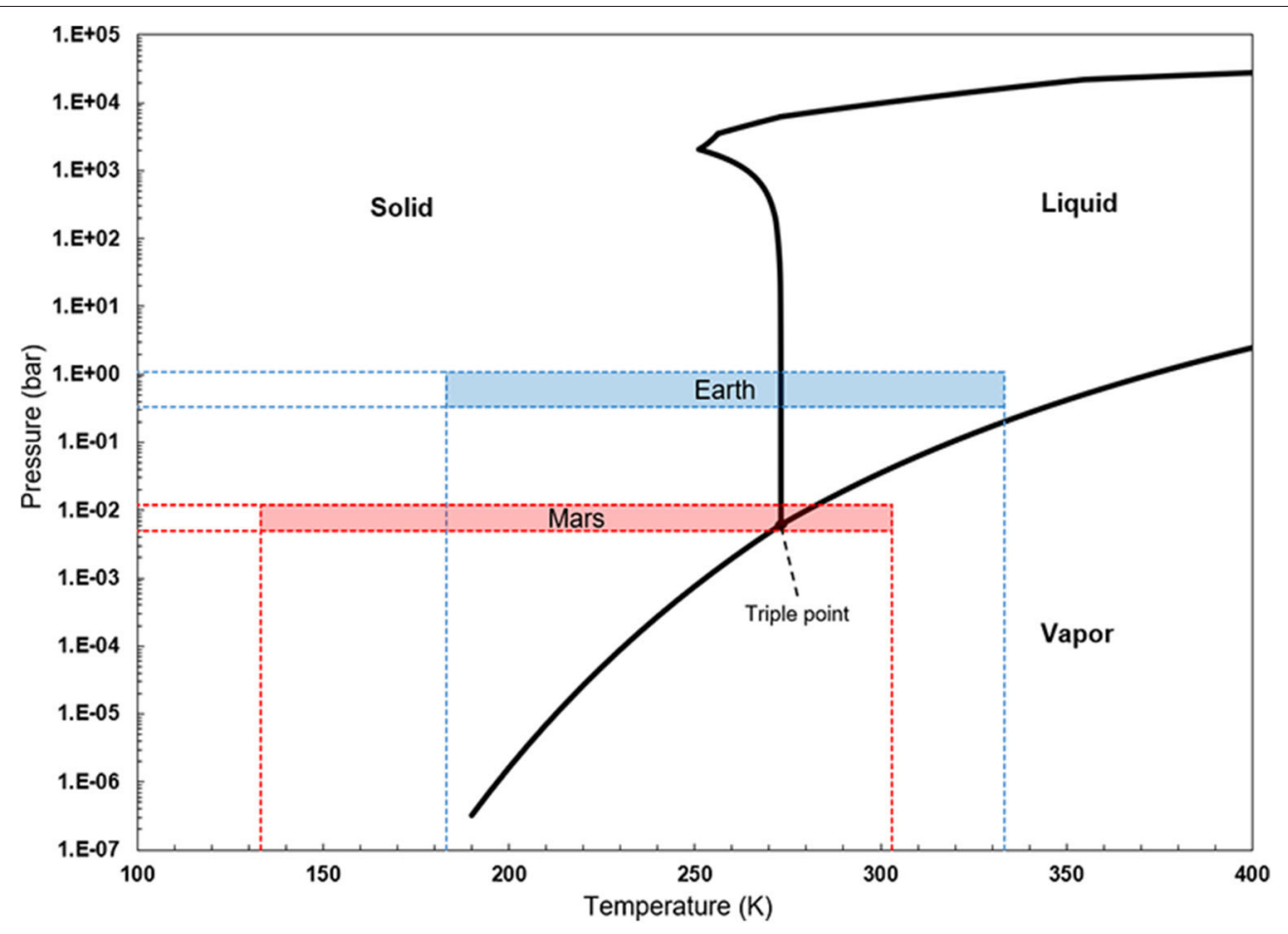

FIGURE 1 | Water's phase diagram, with approximate pressure and temperature ranges found on Earth's and Mars's surfaces. Modified from Verseux (2018).

\section{0 mbar to 1 bar}

Between 100 mbar and 1 bar, bacterial growth inhibition by hypobaria seems weak at most, as illustrated by the following examples. (i) In a study by Schuerger et al. (2013) involving 26 bacterial strains from 22 species, all showed vigorous growth at 100 mbar. (ii) Final cell counts of E. coli and B. subtilis strains after 19 days under 1 bar, 670 mbar, and 330 mbar showed no distinct trend (but growth rates were not assessed) (Pokorny et al., 2005). (iii) Growth rates of B. subtilis 168 were similar at 100 mbar and 1 bar of ambient air (Nicholson et al., 2010). (iv) Total bacterial cell counts in plants' hydroponic solution were unaffected by reducing pressure to 100 mbar, though community-level physiological profiles (the abilities of the microbial community to metabolize individual carbon sources) were altered (MacIntyre, 2013). (v) Under non-limiting partial pressures of $\mathrm{CO}_{2}$, the cyanobacteria Synechocystis sp., Arthrospira platensis, and Anabaena cylindrica could grow at least as efficiently under $100 \mathrm{mbar}$ as under 1 bar (Kanervo et al., 2005; Murukesan et al., 2015).

Consistently, metabolism in S. liquefaciens was constant between 1 bar and 100 mbar of ambient air but largely affected below (Schwendner and Schuerger, 2018). B. subtilis was also shown to induce the SigB-mediated global stress response at 100 mbar and below, but not at 250 mbar or above (Waters et al., 2014).

Fungi may have a similar threshold: inhibition (reduced mycelial growth and delay in germination) of various species increased with decreasing pressure from 133 mbar of ambient air, but behavior was constant between 200 mbar and 1 bar (Apelbaum and Barkai-Golan, 1977; Romanazzi et al., 2001). No growth or germination occurred at $33 \mathrm{mbar}$, though it did at 67 mbar (Apelbaum and Barkai-Golan, 1977).

Interestingly, $100 \mathrm{mbar}$ is roughly the lowest pressure of the troposphere (Holton et al., 1995), where bacteria abound (DeLeon-Rodriguez et al., 2013) and above which the density of microorganisms is expected to be low (as a temperature inversion strongly limits the ascension of aerosols through the tropopause). It may also be worth noting here that, at the onset of the Viking Labeled Release experiment (following first nutrient injection), shown in ground-based tests to support metabolism of numerous terrestrial microorganisms, pressure was about 92 mbar (Levin and Straat, 1976, 1979).

A rough summary of bacterial growth as a function of pressure, as described above, is given in Figure 2.

\section{MECHANISMS BY WHICH LOW PRESSURE AFFECTS BACTERIAL GROWTH}

\section{Desiccation}

The most obvious mechanisms for the effects of low pressure may be those of desiccation. When water does not boil, it can still evaporate if the gas phase above is not saturated with water, at rates increasing with decreasing pressure. It is, however, not the only cause for bacterial inhibition at low pressures: growth of $E$. coli $\mathrm{K} 12$ and B. subtilis 168 in liquid medium was impaired below 


\begin{tabular}{|c|c|c|c|c|}
\hline \multirow{2}{*}{\multicolumn{2}{|c|}{$\begin{array}{l}\text { Mars's surface } \\
\text { Water's } \\
\text { triple point }\end{array}$}} & & Troposphere & \multirow[b]{2}{*}{ sea level } \\
\hline & & & $\begin{array}{l}\text { Summit of } \\
\text { Mt. Everest }\end{array}$ & \\
\hline $\begin{array}{l}\text { No growth documented } \\
\text { (liquid water unstable; } \\
\text { survival possible) }\end{array}$ & $\begin{array}{l}7 \\
\text { Growth possible for a } \\
\text { limited number of species } \\
\text { (low temperatures } \\
\text { needed to maintain liquid } \\
\text { water) }\end{array}$ & $\begin{array}{l}25 \\
\text { Lower limit for growth of } \\
\text { most species } \\
\text { (inhibition decreases as } \\
\text { pressure increases) }\end{array}$ & $\begin{array}{l}100 \\
\text { Little effect of changing } \\
\text { pressure } \\
\text { (provided no partial } \\
\text { pressure is limiting) }\end{array}$ & $\begin{array}{l}1000 \quad \mathrm{P} \text { (mbar) } \\
\text { Bacterial growth } \\
\text { (comment) }\end{array}$ \\
\hline $\begin{array}{l}\text { Cottin et al. 2017; Martins } \\
\text { et al. 2017; de Vera et al. } \\
2019\end{array}$ & $\begin{array}{l}\text { Nicholson et al. 2013; } \\
\text { Schuerger and Nicholson } \\
\text { 2016; Schuerger et al. } \\
2013\end{array}$ & $\begin{array}{l}\text { Nicholson et al. 2010; } \\
\text { Schuerger et al. 2006, } \\
\text { 2013; Schuerger and } \\
\text { Nicholson 2006; Berry et } \\
\text { al. } 2010\end{array}$ & $\begin{array}{l}\text { Schuerger et al. 2013; } \\
\text { Pokorny et al. 2005; } \\
\text { Nicholson et al. 2010; } \\
\text { Kanervo et al. 2005; } \\
\text { Murukesan et al. } 2015\end{array}$ & $\begin{array}{l}\text { References } \\
\text { (non-exhaustive) }\end{array}$ \\
\hline
\end{tabular}

FIGURE 2 | Simplified overview of bacterial growth as a function of pressure. This information is to be taken with caution, given today's paucity of data in this area. See text for details.

100 mbar, and that of the latter was close to detection limit at 25 mbar (Schuerger et al., 2006, 2013; Nicholson et al., 2010).

\section{Partial Pressures}

Part of the effects of low pressure can be attributed to the low partial pressures of non-inert gases, which go down, roughly proportionally, with total pressure (Dalton's law), leading to (again, roughly proportionally) reduced concentrations of dissolved gases in liquid phases (Henry's law).

Unfortunately, low-pressure studies often do not single out the effects of the involved gases' partial pressures. Qin et al. (2014), for instance, showed that the growth of cyanobacteria (Microcystis aeruginosa, Merismopedia sp., and Anabaena spp.) in nitrate-rich medium was reduced at 0.5 bar of ambient air compared to 1 bar. However, the atmospheric composition was unchanged, leading to, notably, a halved $\mathrm{pCO}_{2}$-and $\mathrm{pCO}_{2}$ is limiting even under ambient atmosphere, below about 4 mbar (Murukesan et al., 2015). As another example, an experiment demonstrating the lower rates of methanogenesis at 50 mbar compared to 400 mbar of 3 hydrogenotrophic methanogens, Methanothermobacter wolfeii, Methanosarcina barkeri, and Methanobacterium formicicum (Kral et al., 2011), relied on a 50:50 mixture of $\mathrm{H}_{2}: \mathrm{CO}_{2}$ in both cases. While studies suggest that the partial pressure thresholds for use of $\mathrm{H}_{2}$ and $\mathrm{CO}_{2}$ by hydrogenotrophic methanogens are, respectively, within 0.1-50 mbar-depending on species and culture conditions (Lovley, 1985; Lee and Zinder, 1988; Conrad and Wetter, 1990; Kral et al., 1998; Sprenger et al., 2007) - and below 6 mbar (Chen et al., 2019), both gases become limiting from much higher partial pressures (e.g., Agneessens et al., 2017; Chen et al., 2019).

A few studies, however, have investigated the role played by the partial pressure of specific gases in mediating the effects on microorganisms of a low total pressure.

Some of the most clear-cut evidence comes from microalgae. By contrast with results from Qin et al. (2014), experiments with Chlorella spp. where $\mathrm{pCO}_{2}$ was kept constant (total pressures were adjusted using a non-reactive gas, the nature of which seems not to make a difference with Chlorella spp.; Ammann and Lynch, 1966; Orcutt et al., 1970) suggested a positive impact of lowering the pressure to 250 mbar (Orcutt et al., 1970), and showed no negative impact of lowering it to 565 mbar when $\mathrm{pO}_{2}$ was also kept constant (Niederwieser et al., 2019). Chlorella spp. are eukaryotes, but similar results were observed with cyanobacteria: lowering pressure down to 100 mbar inhibited the growth of Synechocystis sp. under ambient air composition but did not reduce its growth, or that of other cyanobacterial species, when $\mathrm{CO}_{2}$ was not limiting (Kanervo et al., 2005; Murukesan et al., 2015).

Though one of those cyanobacteria, A. cylindrica, is diazotrophic, nitrates were provided in the media; one may wonder how reducing the total pressure with non-limiting $\mathrm{CO}_{2}$ would affect the diazotrophic growth of nitrogen fixers. At 1 bar of total pressure, $\mathrm{pN}_{2}$ became limiting for growth of A. cylindrica and A. variabilis below $500 \mathrm{mbar}$, but growth was still vigorous at 100 mbar (Silverman et al., 2018). Those results are consistent with values obtained by others with noncyanobacterial nitrogen fixers: Klingler et al. (1989) showed that growth rates of Azotobacter vinelandii and Azomonas agilis decreased with decreasing $\mathrm{pN}_{2}$ down from about 400 mbar, but that nitrogen fixation was still possible at 5 mbar (though not at 1 mbar), and MacRae (1977) found an increase in nitrogen fixation in Beijerinckia indica and $B$. lacticogenes with $\mathrm{pN}_{2}$ increasing between 5 and 400 mbar. Consistently, nitrogen fixation by Bradyrhizobium japonicum was reported under a $\mathrm{pN}_{2}$ of 190 mbar, under a total pressure of 250 mbar (MacIntyre, 2013), though quantitative results were not presented.

Further evidence on the role of partial pressures comes from the fact that growth inhibition of E. coli K12 in LB at 50 and 25 mbar was attenuated by the addition of substrates for anaerobic metabolism (Schuerger et al., 2013), suggesting a role of decreased oxygen availability in the effect of reduced total pressure. 
One may be tempted to conclude that the effects of hypobaria on bacteria come from changes in partial pressures of non-inert gases and, in solid media, from desiccation. However, evidence suggests effects independent of both. The addition of substrates for anaerobic metabolism did not, or barely, relieve the lowpressure-induced growth inhibition in Bacillus spp. as it did for E. coli $\mathrm{K} 12$, though the former also are capable of anaerobic metabolism (Schuerger and Nicholson, 2006; Schuerger et al., 2013). Besides, endospores of 2 facultatively anaerobic Bacillus spp., $B$. nealsonii and B. licheniformis, could germinate at 1 bar of a high- $\mathrm{CO}_{2}$ atmosphere but not at 25 mbar of either ambient composition or high $\mathrm{CO}_{2}$ (Schuerger and Nicholson, 2006), further pointing toward $\mathrm{pO}_{2}$-independent effects of low pressure. Consistently, a strain of $B$. subtilis evolved toward higher fitness at $5 \mathrm{kPa}$ had no advantage at 1 bar in oxygenlimited conditions (Nicholson et al., 2010), and the des gene it upregulated at low pressure (and whose deactivation decreased its fitness at $5 \mathrm{kPa}$ ) was not upregulated by low oxygen levels (Fajardo-Cavazos et al., 2012).

Evidence that is less conclusive, but nonetheless worth reporting here, was obtained with other organisms. Various Serratia spp. and Carnobacterium spp. were shown to grow better in 7 mbar of a high- $\mathrm{CO}_{2}$ atmosphere than under 1 bar at the same composition and, in the case of Carnobacterium spp., better than under ambient atmosphere (Nicholson et al., 2013; Schuerger et al., 2013; Schuerger and Nicholson, 2016). However, one cannot rule out, on the basis of the reported data, that those observations are due to $\mathrm{CO}_{2}$ 's toxicity at high partial pressures (e.g., Dixon and Kell, 1989; Kimura et al., 1999; Thomas et al., 2005) and, for Carnobacterium spp., from an advantage of reducing $\mathrm{pO}_{2}$ (compensated for by $\mathrm{CO}_{2}$ toxicity in the 1 bar, high- $\mathrm{CO}_{2}$ control). Increasing $\mathrm{O}_{2}$ concentrations attenuated low-pressure growth inhibition in several fungal species, but not fully: inhibition under $67 \mathrm{mbar}$ at a $\mathrm{pO}_{2}$ of 8 mbar was higher than at 1 bar with the same $\mathrm{pO}_{2}$ (Apelbaum and Barkai-Golan, 1977). In a different study, fungal growth was further delayed by a reduced pressure (135 mbar) of ambient air than under ambient pressure at similar $\mathrm{pO}_{2}$ (Wu and Salunkhe, 1972). However, those results may stem from the reduction in $\mathrm{pCO}_{2}$ rather that in total pressure (see, e.g., Bahn and Mühlschlegel, 2006).

$\mathrm{pCO}_{2}$-independent effects of total pressure were reported in microalgae. First, growth rates of Synechocystis sp. were about 5 times higher within 60-150 mbar of a $100 \%-\mathrm{CO}_{2}$ atmosphere than under ambient air, an increase higher than can be explained by $\mathrm{pCO}_{2}$ alone: at the presumably non-limiting value of 4 mbar, growth increased only 3.5-fold (Murukesan et al., 2015). However, $\mathrm{pO}_{2}$ was not constant, and the lack of photorespiration (which would reduce carbon fixation) might explain such results. Second, growth of Chlamydomonas reinhardtii decreased with pressure between 1 bar and 700 mbar under high $\mathrm{CO}_{2}$ concentrations (Wagner and Posten, 2017). It should however be noted that, although $\mathrm{CO}_{2}$ was presumably non-limiting even at the lowest tested pressures, its concentration $(4.8 \%$ $\mathrm{v} / \mathrm{v}$ ) in the sparging gas-not its partial pressure-was constant between samples.

\section{Physico-Chemical Effects of Low Total Pressure}

The effects of low pressure itself, not accounted for by desiccation and the partial pressures of the component gases, can only be described tentatively: data is scarce.

As suggested by others (Nicholson et al., 2010; Waters et al., 2014; Schwendner and Schuerger, 2018, 2020), one can make tentative inferences from studies on the effects of high pressure on microorganisms. Volume reduction caused by high pressure leads to structural alterations in biomolecules, thereby impacting numerous cellular processes and threatening cell integrity. Membranes are particularly sensitive-their rigidity tends to increase with pressure (Macdonald, 1984; Winter and Jeworrek, 2009) - , but various biomolecules, notably proteins and nucleic acids, may be impacted as well (see Bartlett, 2002; Oger and Jebbar, 2010; Mota et al., 2013). Pressure also affects chemical equilibria and reaction rates: following Le Chatelier's principle, higher pressures stabilize the state corresponding to the lowest volume (see for instance Smeller, 2002). One may expect opposite influences when pressure is reduced, such as a tendency toward volume increase of molecular and cellular structures (consistently, Wagner and Posten, 2017 observed a swelling of C. reinhardtii cells when pressure was abruptly lowered), leading, notably, to a fluidification of plasma membranes.

Further effects may be mediated by changes in gas diffusion and solubility. A beneficial impact of reducing pressure while maintaining the partial pressure of metabolism-supporting gases (e.g., Orcutt et al., 1970; Murukesan et al., 2015) may be due to the fact that diffusion coefficients increase proportionally to decreasing pressure (e.g., Chen and Othmer, 1962). Gas exchanges may thus be enhanced and the microenvironment around cells become more supportive of metabolism. This positive impact has not been systematically observed, possibly because diffusion is not always limiting (e.g., Niederwieser et al., 2019) or because other effects can counterbalance it. For similar reasons, one could expect temperature (with increasing temperatures, diffusion rates increase but solubility decreases) and salts (increasing salt concentrations generally decrease gas solubility; Schumpe, 1993) to affect, when the availability of some gases is near the threshold at which they become limiting, the response of bacteria to low total pressures.

The interplay between pressure, temperature, and salinity is more complex than the above could suggest. Schuerger and Nicholson (2006) noted interactive effects of low pressure, temperature, and gas compositions that could hardly be explained by diffusion and solubility alone. Berry et al. (2010) showed that growth in $\mathrm{CO}_{2}$ atmospheres of a strain of $E$. coli was inhibited by $5 \% \mathrm{MgCl}_{2}$, or $5 \% \mathrm{NaCl}$, at 1 bar, but not at 100 or 25 mbar. While one can hypothesize that growth inhibition came from the combined toxicity of high $\mathrm{CO}_{2}$ and high salt concentrations, the former being relieved at lower pressures, the presented data do not allow for a conclusion. More broadly, much remains to be defined, such as the role played by salts' chaotropicity (see Hallsworth et al., 2003, and Ball and Hallsworth, 2015 for an overview of how chaotropic compounds affect bacteria, and Rummel et al., 2014 for insights in the context 
of Martian habitability), or the joint outcome of temperature and low pressure's influences on membrane fluidity.

Finally, bacterial isolates including Streptomyces spp. grew at 7 mbar (high- $\mathrm{CO}_{2}, 0^{\circ} \mathrm{C}$ ) in presence of soil from their original environment but failed to grow in such conditions after being streak-purified, suggesting that geochemical or biological components from their original surroundings are needed to cope with low pressure (Schuerger and Nicholson, 2016).

Hypobaria thus seems to affect cells even when desiccation is prevented and when partial pressures of non-inert gases are constant, in ways that are dependent on various other physicochemical factors. Owing to their complexity and to the paucity of related data, those ways remain poorly understood.

\section{Bacteriostatic or Bactericidal?}

Desiccation set aside, the effects of low pressure seem bacteriostatic rather than bactericidal: growth inhibition at low pressures tends to be relieved when pressure is brought back to normal (Kanervo et al., 2005; Schuerger and Nicholson, 2006; Nicholson et al., 2010, 2013; Schuerger et al., 2013). A similar observation was made on fungi (Apelbaum and BarkaiGolan, 1977). Exceptions were, however, reported: S. liquefaciens incubated for 49 days under 7 mbar of high- $\mathrm{CO}_{2}$ atmosphere, at $0^{\circ} \mathrm{C}$, did not return to fully normal metabolic activity when back to 1 bar of ambient air, at $30^{\circ} \mathrm{C}$ (Schwendner and Schuerger, 2018), and B. subtilis 168 pre-incubated at 50 mbar grew more slowly when brought back to ambient air than cells not previously exposed to low pressure (Nicholson et al., 2010). In the latter case, growth (which had stopped at a low density at 50 mbar) resumed without a lag phase when returned to ambient air, suggesting that low pressures reversibly inactivate some biomolecules. On the other hand, the slower growth rate suggested a lasting physiological alteration, possibly mediated by damage to cell components that require recovery time (Nicholson et al., 2010).

\section{BACTERIAL ADAPTATION TO HYPOBARIA}

All bacteria are not equal in the face of low pressures. Out of nearly $10^{4}$ colonies from permafrost soil samples, only 6, all Carnobacterium spp., grew under 7 mbar of $\mathrm{CO}_{2}$ (Nicholson et al., 2013). Numerous species seem unable to grow at 25 mbar (Schuerger et al., 2013). Wide differences can be found even within a genus: a strain of $B$. subtilis could germinate and grow under 35 mbar of Earth-normal air but not of a high$\mathrm{CO}_{2}$ atmosphere, while the reverse was true for $B$. nealsonii and B. licheniformis (Schuerger and Nicholson, 2006). Two out of 8 tested Serratia spp. strains could not grow under 7 mbar of $\mathrm{CO}_{2}$ (Schuerger and Nicholson, 2016). Cell differentiation matters, too: under 25 mbar of Earth-normal air composition, vegetative cells of 7 Bacillus spp. grew but endospores of the same strains failed to germinate (Schuerger and Nicholson, 2006).

What enables some bacteria to cope better than others is unclear. Below about 25 mbar, temperatures must be lowered below mesophiles' optimal values to reduce evaporation (whose rates decrease with pressure and increase with temperature) and prevent boiling. At Mars-like pressures, temperatures must be so low-the boiling point of pure water is, for instance, around $2.4^{\circ} \mathrm{C}$ at $7 \mathrm{mbar}$ - that psychrophilic or psychrotrophic properties are required for growth. Equally obvious, a microorganism depending on a given gas cannot grow if the total pressure is below the partial pressure threshold for use of that gas. It is, for instance, safe to assume that the low-pressure threshold for diazotrophic or photosynthetic growth is limited by $\mathrm{pN}_{2}$ or $\mathrm{pCO}_{2}$. Consistent with both considerations, all bacteria grown below 10 mbar were obligate or facultative anaerobes, and many came from cold environments (Nicholson et al., 2013; Schuerger and Nicholson, 2016).

Beyond this, describing coping strategies is tentative. Earth's surface is mostly devoid of environments where abilities to grow at low pressures give an advantage: its lowest pressure, at the top of Mount Everest, is above 0.3 bar (West, 1999). Some microorganisms may evolve mechanisms favoring tropospheric endeavors (Morris et al., 2011; DeLeon-Rodriguez et al., 2013) supporting this is the threshold for effect at 100 mbar described above, which roughly corresponds to the lowest pressure in the troposphere-but selective pressure may be more toward survival and transportation efficiency (e.g., suitability for carriage by air masses, or ability to foster precipitations for faster fallout; Smith, 2013) than multiplication. Even so, selection would only happen down to the vicinity of 100 mbar.

One may thus expect responses to very low pressures to be maladaptive. Transcription analyses are consistent with this. Growing B. subtilis at 50 mbar rather than 1 bar altered the levels of 363 transcripts from several global regulons. Most notable was the strong induction at low pressure of the SigBmediated general stress response regulon, which seemed nonoptimal: inactivation of $\operatorname{sig} B$ did not significantly change fitness at either pressure (Waters et al., 2014). Under a high- $\mathrm{CO}_{2}$ atmosphere at $0^{\circ} \mathrm{C}$, the expression of 184 genes in $S$. liquefaciens differed significantly between $7 \mathrm{mbar}$ and 1 bar (Fajardo-Cavazos et al., 2018). No genes were identified that could be reasoned to facilitate growth at low pressure. Some of the most up-regulated were involved in transport and utilization of various sugars (none of which was present in the medium), and the most strongly downregulated ones were involved in transport of sulfate, or the sulfur-containing amino acid cysteine, which here again was presumed to come from a maladaptive answer.

More broadly, no optimized low-pressure answer has been reported. Schuerger et al. (2013) suggested that organisms likely to cope best at low pressure are, rather than specialized extremophiles, those able to adapt to a broad range of environmental conditions.

One may wonder whether this only comes from the lack of a role for hypobaria in natural selection and whether, if exposed to low pressure over multiple generations, microorganism could evolve toward higher tolerance. Studies suggest a positive answer: the fitness of B. subtilis at 50 mbar of ambient air had increased after 1,000 generations (Nicholson et al., 2010), and in large part within the first 200 generations (Waters et al., 2015).

Unfortunately, the molecular basis for this adaptation is unclear. Microarray analyses revealed a higher transcription of the des, desK, and desR genes, encoding, respectively, the Des membrane fatty acid desaturase, the DesK sensor kinase, and the DesR response regulator. Consistently, lowered pressure 
caused an up-regulation of des mRNA levels in the evolved strain only, and deactivating the des gene slightly reduced its fitness at 50 mbar (Fajardo-Cavazos et al., 2012). Such a result is somewhat surprising: reducing pressure tends to increase membrane fluidity (Macdonald, 1984), and the des-desKR system mediates an acute response that fluidifies membranes when temperatures go down, counterbalancing cold's tendency to rigidify them (Aguilar et al., 2001). In the ancestral strain, reducing the pressure led to seemingly conflicting responses: an increase in the proportion of saturated fatty acids (which would tend to increase rigidity) accompanied by an increase in the proportion of anteiso-fatty acids (which would tend to increase fluidity). At $50 \mathrm{mbar}$, fatty acid membrane compositions were similar in the ancestral and evolved strains, suggesting that adaptation did not come from there (though the evolved strain had a lower proportion of anteiso-fatty acids at 1 bar, which may give an initial advantage following a drop in pressure).

Whole-genome sequencing revealed that the adapted strain had amino acid-altering mutations in the coding sequences of 7 genes, 2 of which are involved in the maintenance of cell wall integrity, and a 9-nucleotide in-frame deletion in the $r n j B$ gene that encodes a component of the RNA degradosome-and whose knockout increased competitive fitness of $B$. subtilis at both low pressure and 1 bar (Waters et al., 2015). However, whether and how those different mutations may enhance growth specifically at low pressure remains to be elucidated, and most of the increase in fitness occurred before those mutations spread in the evolving population.

\section{CONCLUDING REMARKS}

Implications for potential metabolism on Mars and in the troposphere of bacteria's capabilities to grow at low pressure were discussed elsewhere (Nicholson et al., 2013; Schuerger et al., 2013; Waters et al., 2014; Schuerger and Nicholson, 2016; Schwendner and Schuerger, 2020), but less so the opportunities for BLSS. Results presented above suggest that microbial modules in crewed compartments of future space vehicle and habitats would be little affected by the envisioned reduced pressure (NASA, 2006) itself; more important would be the partial pressures of the component gases.

Lower pressures would offer advantages for BLSS deployed outside, such as cyanobacterium-based ones (CyBLiSS): it has been argued that some species of diazotrophic, rock-weathering cyanobacteria could be used as a basis for life-support systems

\section{REFERENCES}

Agneessens, L. M., Ottosen, L. D. M., Voigt, N. V., Nielsen, J. L., de Jonge, N., Fischer, C. H., et al. (2017). In-situ biogas upgrading with pulse $\mathrm{H}_{2}$ additions: the relevance of methanogen adaption and inorganic carbon level. Bioresour. Technol. 233, 256-263. doi: 10.1016/j.biortech.2017.02.016

Aguilar, P. S., Hernandez-Arriaga, A. M., Cybulski, L. E., Erazo, A. C., and De Mendoza, D. (2001). Molecular basis of thermosensing: a two-component signal transduction thermometer in Bacillus subtilis. EMBO J. 20, 1681-1691. doi: 10.1093/emboj/20.7.1681 on Mars that would rely on local resources-atmospheric gases, water mined on site, and mineral nutrients from the regolith-, thereby greatly reducing the mass of consumables to be sent from Earth (Verseux et al., 2016b). One of the factors that will determine the efficiency of CyBLiSS is the behavior of cyanobacteria under non-Earth atmospheres. On the one hand, growing them under atmospheric conditions close to Mars's (low total pressure, high $\mathrm{pCO}_{2}$, low $\mathrm{pN}_{2}$ ) would simplify the system, minimize the mass of structural materials and consumables, and lower the risk of organic matter leakage (Lehto et al., 2006; Verseux et al., 2016b). On the other hand, changes in gas composition and pressure affect cyanobacterial behavior. Opening cultures directly to the Martian atmosphere is, of course, excluded: both total pressure and $\mathrm{pN}_{2}$ are too low. However, changing the $\mathrm{CO}_{2} / \mathrm{N}_{2}$ ratio and pressurizing slightly, both of which could be done with technologies routinely used on Earth, could suffice. A total pressure of 100 mbar or below, with a few percent $\mathrm{CO}_{2}$, is not expected to be limiting per se; growth would presumably depend largely, atmosphere-wise, on $\mathrm{pN}_{2}$. What atmospheric conditions offer the most relevant compromise between engineering and biology is currently being investigated.

Overall, while the impacts of extreme conditions on bacteria have been quite intensely studied (e.g., Rothschild and Mancinelli, 2001; Harrison et al., 2013), high hypobaria has been largely neglected, owing in large part to its absence from Earth's surface and to the need for specific experimental hardware. Only a limited number of organisms, isolated from a small set of environments, have been measured against it. The mechanisms mediating the effects of low pressure, and their interactions, are poorly understood. How far the low-pressure limits of bacteria could be pushed, by genetic engineering or directed evolution, is unknown. Much remains to be discovered in the field of lowpressure microbiology. Here is a call for interested researchers to join this investigation.

\section{AUTHOR CONTRIBUTIONS}

CV conceived and wrote the manuscript.

\section{ACKNOWLEDGMENTS}

CV acknowledges funding from the Alexander von Humboldt Foundation, and thanks both reviewers for their valuable comments. 
Bahn, Y. S., and Mühlschlegel, F. A. (2006). $\mathrm{CO}_{2}$ sensing in fungi and beyond. Curr. Opin. Microbiol. 9, 572-578. doi: 10.1016/j.mib.2006.09.003

Ball, P., and Hallsworth, J. E. (2015). Water structure and chaotropicity: their uses, abuses and biological implications. Phys. Chem. Chem. Phys. 17, 8297-8305. doi: 10.1039/C4CP04564E

Bartlett, D. H. (2002). Pressure effects on in vivo microbial processes. Biochimi. Biophys. Acta 1595, 367-81. doi: 10.1016/S0167-4838(01)00357-0

Beblo-Vranesevic, K., Bohmeier, M., Schleumer, S., Rabbow, E., Perras, A. K., Moissl-Eichinger, C., et al. (2020). Impact of simulated Martian conditions on (facultatively) anaerobic bacterial strains from different Mars analogue sites. Curr. Issues Mol. Biol. 38, 103-122. doi: 10.21775/cimb.038.103

Berry, B. J., Jenkins, D. G., and Schuerger, A. C. (2010). Effects of simulated Mars conditions on the survival and growth of Escherichia coli and Serratia liquefaciens. Appl. Environ. Microbiol. 76, 2377-2386. doi: 10.1128/AEM.02147-09

Billi, D., and Potts, M. (2002). Life and death of dried prokaryotes. Res. Microbiol. 153, 7-12. doi: 10.1016/S0923-2508(01)01279-7

Boston, P. J. (1981). Low-pressure greenhouses and plants for a manned research station on Mars. J. Br. Interplanet. Soc. 34:189.

Burg, S. P. (2004). Postharvest Physiology and Hypobaric Storage of Fresh Produce. Cambridge, MA: Cabi Pulishing. doi: 10.1079/9780851998015.0000

Chen, N. H., and Othmer, D. F. (1962). New generalized equation for gas diffusion coefficient. J. Chem. Eng. Data 7, 37-41. doi: 10.1021/je60012a011

Chen, X., Ottosen, L. D. M., and Kofoed, M. V. W. (2019). How low can you go: methane production of Methanobacterium congolense at low $\mathrm{CO}_{2}$ concentrations. Front. Bioeng. Biotechnol. 7:34. doi: 10.3389/fbioe.2019.00034

Conrad, R., and Wetter, B. (1990). Influence of temperature on energetics of hydrogen metabolism in homoacetogenic, methanogenic, and other anaerobic bacteria. Arch. Microbiol. 155, 94-98. doi: 10.1007/BF00291281

Cortesão, M., Fuchs, F. M., Commichau, F. M., Eichenberger, P., Schuerger, A. C., Nicholson, W. L., et al. (2019). Bacillus subtilis spore resistance to simulated Mars surface conditions. Front. Microbiol. 10:333. doi: $10.3389 /$ fmicb. 2019.00333

Cottin, H., Kotler, J. M., Bartik, K., Cleaves, H. J., Cockell, C. S., de Vera, J.-P., et al. (2017). Astrobiology and the possibility of life on Earth and elsewhere. Space Sci. Rev. 209, 1-42. doi: 10.1007/s11214-015-0196-1

de Vera, J.-P., Alawi, M., Backhaus, T., Baqué, M., Billi, D., Böttger, U., et al. (2019). Limits of life and the habitability of Mars: the ESA space experiment BIOMEX on the ISS. Astrobiology 19, 145-157. doi: 10.1089/ast.2018.1897

de Vera, J.-P., Möhlmann, D., Butina, F., Lorek, A., Wernecke, R., and Ott, S. (2010). Survival potential and photosynthetic activity of lichens under Mars-like conditions: a laboratory study. Astrobiology 10, 215-227. doi: 10.1089 /ast.2009.0362

de Vera, J.-P., Schulze-Makuch, D., Khan, A., Lorek, A., Koncz, A., Möhlmann, D., et al. (2014). Adaptation of an Antarctic lichen to Martian niche conditions can occur within 34 days. Planet. Space Sci. 98, 182-190. doi: 10.1016/j.pss.2013.07.014

DeLeon-Rodriguez, N., Lathem, T. L., Rodriguez,-R., L. M., Barazesh, J. M., Anderson, B. E., et al. (2013). Microbiome of the upper troposphere: species composition and prevalence, effects of tropical storms, and atmospheric implications. Proc. Natl. Acad. Sci. U.S.A. 110, 2575-2580. doi: $10.1073 /$ pnas. 1212089110

Dixon, N. M., and Kell, D. B. (1989). The inhibition by $\mathrm{CO}_{2}$ of the growth and metabolism of micro-organisms. J. Appl. Bacteriol. 67, 109-136. doi: 10.1111/j.1365-2672.1989.tb03387.x

Fajardo-Cavazos, P., Morrison, M. D., Miller, K. M., Schuerger, A. C., and Nicholson, W. L. (2018). Transcriptomic responses of Serratia liquefaciens cells grown under simulated Martian conditions of low temperature, low pressure, and $\mathrm{CO}_{2}$-enriched anoxic atmosphere. Sci. Rep. 8:14938. doi: $10.1038 / \mathrm{s} 41598-018-33140-4$

Fajardo-Cavazos, P., Waters, S. M., Schuerger, A. C., George, S., Marois, J. J., and Nicholson, W. L. (2012). Evolution of Bacillus subtilis to enhanced growth at low pressure: up-regulated transcription of des-desKR, encoding the fatty acid desaturase system. Astrobiology 12, 258-270. doi: 10.1089/ast. 2011.0728

Godia, F., Albiol, J., Montesinos, J. L., and Pérez, J. (2002). MELISSA: a loop of interconnected bioreactors to develop life support in space. J. Biotechnol. 99, 319-330. doi: 10.1016/S0168-1656(02)00222-5
Haberle, R. M., Mckay, C. P., Schaeffer, J., Cabrol, N. A., Grin, E. A., Zent, A. P., et al. (2001). On the possibility of liquid water on present-day Mars. J. Geophys. Res. 106, 317-326. doi: 10.1029/2000JE001360

Hallsworth, J. E., Heim, S., and Timmis, K. N. (2003). Chaotropic solutes cause water stress in Pseudomonas putida. Environ. Microbiol. 5, 1270-1280. doi: 10.1111/j.1462-2920.2003.00478.x

Harri, A. M., Genzer, M., Kemppinen, O., Kahanpää, H., Gomez-Elvira, J., Rodriguez-Manfredi, J. A., et al. (2014). Pressure observations by the Curiosity rover: initial results. J. Geophys. Res. E Planets 119, 82-92. doi: 10.1002/2013JE004423

Harrison, J. P., Gheeraert, N., Tsigelnitskiy, D., and Cockell, C. S. (2013). The limits for life under multiple extremes. Trends Microbiol. 21, 204-212. doi: 10.1016/j.tim.2013.01.006

Haynes, W. M. (ed). (2017). CRC Handbook of Chemistry and Physics. 97th Edn. Boca Raton, FL: CRC Press. doi: 10.1201/9781315380476

Hecht, M. H. (2002). Metastability of liquid water on Mars. Icarus 156, 373-386. doi: 10.1006/icar.2001.6794

Hendrickx, L., and Mergeay, M. (2007). From the deep sea to the stars: human life support through minimal communities. Curr. Opin. Microbiol. 10, 231-237. doi: 10.1016/j.mib.2007.05.007

Holton, J. R., Haynes, P. H., Mcintyre, M. E., Douglass, A. R., and Rood, B. (1995). Stratosphere-troposphere exchange. Rev. Geophys. 33, 403-439. doi: 10.1029/95RG02097

Kanervo, E., Lehto, K., Ståhle, K., Lehto, H., and Mäenpää, P. (2005). Characterization of growth and photosynthesis of Synechocystis sp. PCC 6803 cultures under reduced atmospheric pressures and enhanced $\mathrm{CO}_{2}$ levels. Int. J. Astrobiol. 4, 97-100. doi: 10.1017/S1473550405002466

Kimura, B., Yoshiyama, T., and Fujii, T. (1999). Carbon dioxide inhibition of Escherichia coli and Staphylococcus aureus on a pH-adjusted surface in a model system. J. Food Sci. 64, 367-370. doi: 10.1111/j.1365-2621.1999.tb15902.x

Kleina, A., Perycz, M., Wasniowski, Q., and Kaczmarzyk, M. (2019). Bluegreen cyanobacteria Plectonema boryanum UTEX B 485 cultivation under low pressure anaerobic conditions (with a high content of carbon dioxide) simulating Martian atmosphere. IAC 2019, 21-25.

Klingler, J. M., Mancinelli, R. L., and White, M. R. (1989). Biological nitrogen fixation under primordial Martian partial pressures of dinitrogen. Adv. Space Res. 9, 173-176. doi: 10.1016/0273-1177(89)90225-1

Kral, T., Altheide, T. S., Lueders, A. E., and Schuerger, A. C. (2011). Low pressure and desiccation effects on methanogens: implications for life on Mars. Planet. Space Sci. 59, 264-270. doi: 10.1016/j.pss.2010.07.012

Kral, T. A.,Brink, K. M., Miller, S. L., and Mckay, C. P. (1998). Hydrogen consumption by methanogens on the early Earth. Origins Life Evol Biosph. 28, 311-319. doi: 10.1023/A:1006552412928

Lee, M. J., and Zinder, S. H. (1988). Hydrogen partial pressures in a thermophilic acetate-oxidizing methanogenic coculture. Appl. Environ. Microbiol. 54, 1457-1461. doi: 10.1128/AEM.54.6.1457-1461.1988

Lehto, K. M., Lehto, H. J., and Kanervo, E. A. (2006). Suitability of different photosynthetic organisms for an extraterrestrial biological life support system. Res. Microbiol. 157, 69-76. doi: 10.1016/j.resmic.2005.07.011

Levin, G. V., and Straat, P. A. (1976). Labeled release - an experiment in radiorespirometry. Orig. Life 7, 293-311. doi: 10.1007/BF00926948

Levin, G. V., and Straat, P. A. (1979). Laboratory simulations of the Viking Labeled Release experiment: kinetics following second nutrient injection and the nature of the gaseous end product. J. Mol. Evol. 14, 185-197. doi: 10.1007/BF01732377

Lovley, D. R. (1985). Minimum threshold for hydrogen metabolism in methanogenic bacteria. Appl. Environ. Microbiol. 49, 1530-1531. doi: 10.1128/AEM.49.6.1530-1531.1985

Macdonald, A. G. (1984). The effects of pressure on the molecular structure and physiological functions of cell membranes. Philos. Trans. R. Soc. Lond. B Biol. Sci. 304, 47-68. doi: 10.1098/rstb.1984.0008

MacIntyre, O. J. (2013). Microbial Dynamics and Plant-Microbe Interactions in a Hypobaric Higher-Plant Chamber: Implications for Advanced Life Support in Space. (Ph.D. thesis), University of Guelph, Guelph, ON: Canada

MacRae, I. C. (1977). Influence of partial pressures of acetylene and nitrogen upon nitrogenase activity of species of Beijerinckia. Aust. J. Biol. Sci. 30, 593-596. doi: 10.1071/BI9770593

Martínez, G. M., Newman, C. N., De Vicente-Retortillo, A., Fischer, E., Renno, N. O., Richardson, M. I., et al. (2017). The modern near-surface Martian climate: 
a review of in-situ meteorological data from Viking to Curiosity. Space Sci. Rev. 212, 295-338. doi: 10.1007/s11214-017-0360-x

Martins, Z., Cottin, H., Kotler, J. M., Carrasco, N., Cockell, S. S., de la Torre Noetzel, R., et al. (2017). Earth as a tool for astrobiology-a European perspective. Space Sci. Rev. 209, 43-81. doi: 10.1007/s11214-017-0369-1

McKay, C. P., Toon, O. B., and Kasting, J. F. (1991). Making Mars habitable. Nature 352, 489-496. doi: 10.1038/352489a0

Morris, C. E., Sands, D. C., Bardin, M., Jaenicke, R., Vogel, B., Leyronas, C., et al. (2011). Microbiology and atmospheric processes: research challenges concerning the impact of airborne micro-organisms on the atmosphere and climate. Biogeosciences 8, 17-25. doi: 10.5194/bg-8-17-2011

Mota, M. J., Lopes, R. P., Delgadillo, I., and Saraiva, J. A. (2013). Microorganisms under high pressure - adaptation, growth and biotechnological potential. Biotechnol. Adv. 31, 1426-1434. doi: 10.1016/j.biotechadv.2013.06.007

Murukesan, G., Leino, H., Mäenpää, P., Ståhle, K., Raksajit, W., Lehto, H. J., et al. (2015). Pressurized Martian-like pure $\mathrm{CO}_{2}$ atmosphere supports strong growth of cyanobacteria, and causes significant changes in their metabolism. Origins Life Evol. Biosph. 46, 119-131. doi: 10.1007/s11084-015-9458-x

NASA (2006). Recommendations for Exploration Spacecraft Internal Atmospheres: The Final Report of the NASA Exploration Atmospheres Working Group (EAWG) JSC-63309. Houston.

Nicholson, W. L., Fajardo-Cavazos, P., Fedenko, J., Ortíz-Lugo, J. L., RivasCastillo, A., Waters, S. M., et al. (2010). Exploring the low-pressure growth limit: evolution of Bacillus subtilis in the laboratory to enhanced growth at 5 kilopascals. Appl. Environ. Microbiol. 76, 7559-7565. doi: 10.1128/AEM.01126-10

Nicholson, W. L., Krivushin, K., Gilichinsky, D., and Schuerger, A. C. (2013). Growth of Carnobacterium spp. from permafrost under low pressure, temperature, and anoxic atmosphere has implications for Earth microbes on Mars. Proc. Natl. Acad. Sci. U.S.A. 110, 666-671. doi: 10.1073/pnas.1209793110

Niederwieser, T., Kociolek, P., Hoehn, A., and Klaus, D. (2019). Effect of altered nitrogen partial pressure on Chlorellaceae for spaceflight applications. Algal Res. 41:101543. doi: 10.1016/j.algal.2019.101543

Norcross, J., Norsk, P., Law, J., Arias, D., Conkin, J., Perchonok, M., et al. (2013). Effects of the 8 psia / $32 \% \mathrm{O}_{2}$ Atmosphere on the Human in the Spaceflight Environment. NASA/TM-2013-217377. Available online at: https://ntrs.nasa. gov/archive/nasa/casi.ntrs.nasa.gov/20130013505.pdf (accessed February 22, 2020).

Oger, P. M., and Jebbar, M. (2010). The many ways of coping with pressure. Res. Microbiol. 161, 799-809. doi: 10.1016/j.resmic.2010.09.017

Orcutt, D. M., Richardson, B., and Holden, R. D. (1970). Effects of hypobaric and hyperbaric helium atmospheres on the growth of Chlorella sorokiniana. Appl. Microbiol. 19, 182-83. doi: 10.1128/AEM.19.1.182-183. 1970

Orosei, R., Lauro, S. E., Pettinelli, E., Cicchetti, A., Coradini, M., Cosciotti, B., et al. (2018). Radar evidence of subglacial liquid water on Mars. Science 361, 490-493. doi: $10.1126 /$ science.aar7268

Paul, L.-A., and Ferl, R. J. (2006). The biology of low atmospheric pressure implications for exploration mission design and advanced life support. Gravit. Space Biol. 19, 3-18.

Pokorny, N. J., Boulter-Bitzer, J. I., Hart, M. M., Storey, L., Lee, H., and Trevors, J. T. (2005). Hypobaric bacteriology: growth, cytoplasmic membrane polarization and total cellular fatty acids in Escherichia coli and Bacillus subtilis. Int. J. Astrobiol. 4, 187-193. doi: 10.1017/S14735504050 02727

Qin, L., Yu, Q., Ai, W., Tang, Y., Ren, J., and Guo, S. (2014). Response of cyanobacteria to low atmospheric pressure. Life Sci. Space Res. 3, 55-62. doi: 10.1016/j.lssr.2014.09.001

Richards, J. T., Corey, K. A., and Paul, A. L. (2006). Exposure of Arabidopsis thaliana to hypobaric environments: implications for low-pressure bioregenerative life support systems for human exploration missions and terraforming. Astrobiology 6, 851-66. doi: 10.1089/ast.2006.6.851

Romanazzi, G., Nigro, F., Ippolito, A., and Salerno, M. (2001). Effect of short hypobaric treatments on postharvest rots of sweet cherries, strawberries and table grapes. Postharvest Biol. Technol. 22, 1-6. doi: 10.1016/S0925-5214(00)00188-5

Rothschild, L. J., and Mancinelli, R. L. (2001). Life in extreme environments. Nature 409, 1092-1101. doi: 10.1038/35059215
Rummel, J. D., Beaty, D. W., Jones, M. A., Bakermans, C., Barlow, N. G., Boston, P. J., et al. (2014). A new analysis of Mars "Special Regions": findings of the second MEPAG Special Regions Science Analysis Group (SR-SAG2). Astrobiology 14, 887-968. doi: 10.1089/ast.2014.1227

Schuerger, A. C., Berry, B., and Nicholson, W. L. (2006). "Terrestrial bacteria typically recovered from Mars spacecraft do not appear able to grow under simulated Martian conditions," in Lunar and Planetary Science XXXVII (Houston, TX: Lunar and Planetary Institute), 37.

Schuerger, A. C., and Nicholson, W. L. (2006). Interactive effects of hypobaria, low temperature, and $\mathrm{CO}_{2}$ atmospheres inhibit the growth of mesophilic Bacillus spp. under simulated Martian conditions. Icarus 185, 143-152. doi: 10.1016/j.icarus.2006.06.014

Schuerger, A. C., and Nicholson, W. L. (2016). Twenty species of hypobarophilic bacteria recovered from diverse soils exhibit growth under simulated Martian conditions at $0.7 \mathrm{KPa}$. Astrobiology 16, 964-976. doi: 10.1089/ast.2016.1587

Schuerger, A. C., Ulrich, R., Berry, B. J., and Nicholson, W. L. (2013). Growth of Serratia liquefaciens under $7 \mathrm{mbar}, 0^{\circ} \mathrm{C}$, and $\mathrm{CO}_{2}$-enriched anoxic atmospheres. Astrobiology 13, 115-131. doi: 10.1089/ast.2011.0811

Schumpe, A. (1993). The estimation of gas solubilities in salt solutions. Chem. Eng. Sci. 48, 153-158. doi: 10.1016/0009-2509(93)80291-W

Schwendner, P., and Schuerger, A. C. (2018). Metabolic fingerprints of Serratia liquefaciens under simulated Martian conditions using biolog GN2 microarrays. Sci. Rep. 8, 1-14. doi: 10.1038/s41598-018-33856-3

Schwendner, P., and Schuerger, A. C. (2020). Exploring microbial activity in low-pressure environments. Curr. Issues Mol. Biol. 38, 163-196. doi: $10.21775 / \mathrm{cimb} .038 .163$

Silverman, S. N., Kopf, S. H.,Bebout, B. M., Gordon, R., and Som, S. M. (2018). Morphological and isotopic changes of heterocystous cyanobacteria in response to $\mathrm{N}_{2}$ partial pressure. Geobiology 17, 60-75. doi: 10.1111/gbi.12312

Smeller, L. (2002). Pressure-temperature phase diagrams of biomolecules. Biochim. Biophys. Acta 1595, 11-29. doi: 10.1016/S0167-4838(01)00332-6

Smith, D. J. (2013). Microbes in the upper atmosphere and unique opportunities for astrobiology research. Astrobiology 13, 981-990. doi: 10.1089/ast.2013.1074

Smith, D. J., Griffin, D. W., and Schuerger, A. C. (2010). Stratospheric microbiology at $20 \mathrm{~km}$ over the Pacific Ocean. Aerobiologia 26, 35-46. doi: 10.1007/s10453-009-9141-7

Sori, M. M., and Bramson, A. M. (2019). Water on Mars, with a grain of salt: local heat anomalies are required for basal melting of ice at the south pole today. Geophys. Res. Lett. 46, 1222-1231. doi: 10.1029/2018GL080985

Sprenger, W. W., Hackstein, J. H. P., and Keltjens, J. T. (2007). The competitive success of Methanomicrococcus blatticola, a dominant methylotrophic methanogen in the cockroach hindgut, is supported by high substrate affinities and favorable thermodynamics. FEMS Microbiol. Ecol. 60, 266-275. doi: 10.1111/j.1574-6941.2007.00287.x

Steinle, A., Knittel, K., Felber, N., Casalino, C., de Lange, G., Tessarolo, C., et al. (2018). Life on the edge: active microbial communities in the Kryos $\mathrm{MgCl}_{2}$-brine basin at very low water activity. ISME J. 12, 1414-1426. doi: 10.1038/s41396-018-0107-z

Stevenson, A., Burkhardt, J., Cockell, C. S., Cray, J. A., Dijksterhuis, J., FoxPowell, M., et al. (2015). Multiplication of microbes below 0.690 water activity: implications for terrestrial and extraterrestrial life. Environ. Microbiol. 17, 257-277. doi: 10.1111/1462-2920.12598

Stevenson, A., Hamill, P. G., Kane, C. J. O., Kminek, G., Rummel, J. D., Voytek, M. A., et al. (2017). Aspergillus penicillioides differentiation and cell division at 0.585 water activity. Environ. Microbiol. 19. 687-697. doi: 10.1111/1462-2920.13597

Thomas, D. J., Boling, J., Boston, P. J., Campbell, K. A., McSpadden, T., McWilliams, L., et al. (2006). Extremophiles for ecopoiesis: desirable traits for and survivability of pioneer Martian organisms. Gravit. Space Biol. 19, 91-104.

Thomas, D. J., Sullivan, S. L., Sprice, A. L., and Zimmerman, S. M. (2005). Common freshwater cyanobacteria grow in $100 \% \mathrm{CO}_{2}$. Astrobiology 5, 66-74. doi: 10.1089/ast.2005.5.66

Verseux, C. (2018). Resistance of cyanobacteria to space and mars environments, in the frame of the EXPOSE-R2 space mission and beyond. (Ph.D. thesis), University of Rome "Tor Vergata," Rome, Italy.

Verseux, C., Baqué, M., Lehto, K., de Vera, J.-P., Rothschild, L. J., and Billi, D. (2016b). Sustainable life support on Mars - the potential roles of cyanobacteria. Int. J. Astrobiol. 15, 65-92. doi: 10.1017/S147355041500021X 
Verseux, C., Paulino-Lima, I., Baqué, M., Billi, D., and Rothschild, L. J. (2016a). "Synthetic biology for space exploration: promises and societal implications," in Ambivalences of Creating Life. Societal and Philosophical Dimensions of Synthetic Biology, eds K. Hagen, M. Engelhard, and G. Toepfer (Cham: Springer-Verlag), 73-100. doi: 10.1007/978-3-319-21088-9_4

Wagner, I., and Posten, C. (2017). Pressure reduction affects growth and morphology of Chlamydomonas reinhardtii. Eng. Life Sci. 17, 552-560. doi: 10.1002/elsc.201600131

Waters, S. M., Robles-Martínez, J. A., and Nicholson, W. L. (2014). Exposure of Bacillus subtilis to low pressure (5 kilopascals) induces several global regulons, including those involved in the SigB-mediated general stress response. Appl. Environ. Microbiol. 80, 4788-4794. doi: 10.1128/AEM. 00885-14

Waters, S. M., Zeigler, D. R., and Nicholson, W. L. (2015). Experimental evolution of enhanced growth by Bacillus subtilis at low atmospheric pressure: genomic changes revealed by whole-genome sequencing. Appl. Environ. Microbiol. 81, 7525-7532. doi: 10.1128/AEM.01690-15
West, J. B. (1999). Barometric pressures on Mt. Everest: new data and physiological significance. J. Appl. Phys. 86, 1062-1066. doi: 10.1152/jappl.1999.86.3.1062

Winter, R., and Jeworrek, C. (2009). Effect of pressure on membranes. Soft Matter 5, 3157-3173. doi: 10.1039/b901690b

Wu, M. T., and Salunkhe, D. K. (1972). Fungistatic effects of sub-atmospheric pressures. Experientia 28, 866-867. doi: 10.1007/BF01923180

Conflict of Interest: The author declares that the research was conducted in the absence of any commercial or financial relationships that could be construed as a potential conflict of interest.

Copyright $\odot 2020$ Verseux. This is an open-access article distributed under the terms of the Creative Commons Attribution License (CC BY). The use, distribution or reproduction in other forums is permitted, provided the original author(s) and the copyright owner(s) are credited and that the original publication in this journal is cited, in accordance with accepted academic practice. No use, distribution or reproduction is permitted which does not comply with these terms. 